Symptomatic infection developed in 16 of the 45 untreated bacteriuric women $(36 \%)$. Loin pain and fever developed in only two of these subjects, whereas in the remainder the symptoms were frequency and dysuria. Comparison of these findings with the natural history of asymptomatic significant bacteriuria in pregnancy shows that the total incidence of symptomatic infection is similar. The distinguishing feature between the natural history of asymptomatic significant bacteriuria in pregnant and non-pregnant women is the severity of symptoms. Asscher et al. (1966) showed that in pregnancy the urine is continuously maintained at optimal $p \mathrm{H}$ for the growth of urinary pathogens. It may be that the greater severity of symptomatic infections arising in pregnant bacteriuric women is related to this.

A single course of treatment initially cured bacteriuria in $80 \%$ of cases, but was soon followed by relapses and reinfections, particularly in women who had been shown to have radiological abnormalities. One year after treatment, therefore, the cure rates among treated and untreated bacteriuric subjects no longer showed a significant difference. Not surprisingly, therefore, treatment failed to prevent the development of symptoms of overt infection. Moreover, it has been shown that the reinfections which followed treatment were more commonly associated with the development of symptoms than the persistent or relapsing infections in the untreated or unsuccessfully treated subjects. This would suggest that bacteriuric women may have developed tolerance to the particular organism harboured in their urinary tract and that treatment can temporarily upset this equilibrium. The occurrence of tolerance to the pyrogenic substances of Gram-negative bacteria in animals and humans with urinary tract infections has been demonstrated by McCabe (1963) and may explain the more frequent development of symptoms , in subjects who are reinfected after treatment.

Our observations suggest that a search for significant bacteriuria in non-pregnant female populations does not satisfy either of the principal requirements of a good screening procedure. In many instances it fails to detect urinary tract infection at an early and reversible stage of its natural history (Sussman et al., 1969), and treatment suitable for use on a large scale fails to alter its natural history. The present study still leaves an important gap in our understanding of the clinical significance of bacteriuria-namely, its relationship to the ultimate development of scarring and contraction of the kidneys and of renal failure. It is hoped that long-term follow-up of the bacteriuric and control subjects of this study will help us to provide an answer. At present it scems likely that even if persistent bacteriuria did lead to progressive renal damage its eradication would be difficult, costly, time-consuming, and probably hazardous.

We are indebted to Professor A. L. Cochrane, Professor H. Scarborough, and Professor Scott Thomson for their help and encouragement. We gratefully acknowledge the help of Mrs. M. Hare, Mrs. L. Pitman, Mrs. A. Richards, Miss S. Chick, Mrs. G. Elliott, and the staff of the department of radiology of the Cardiff Royal Infirmary. The Kidney Research Unit Foundation for Wales generously donated a van to facilitate home visiting. The study was supported by the Medical Research Council and the Norwich Pharmacal Company, Norwich, New York. We also thank Beecham Research Laboratories for their co-operation.

\section{F.EFERENCES}

Asscher, A. W., Sussman, M., Waters, W. E., Davis, R. H., and Chick, S. (1966). Lancet, 2, 1037.

Cox, C. E., and Hinman, F. (1965). In Progress in Pyelonephritis, edited by E. H. Kass, p. 563 . F. A. Davis, Philadelphia.

Freedman, L. R., Phair, J. P. Seki, M., Hamilton, H. B., Nefzger, M. Ded., 37, 262.

Kass, E. H (1960). Arch intern. Med $105,194$.

Kass, E. H. (1960). Arch. intern. Med., 10, 194. G. (1965). In Progress in Pyelonephritis, edited by E. H. Kass, p. 3. F. A. Davis Co., in Pyelonep

McCabe, W. R. (1963). f. clin. Invest., 42, 618

Sussman, M., et al. (1969). Brit. med. f., 1, 799.

* Pfizer Research Fellow, now Senior Surgical Registrar.

+ Research Fellow, Department of Surgery.

$¥$ Senior Lecturer and Consultant Surgeo

Lecturer, Department of Haematology.

Reader and Consultant Haematologist.

King's College Hospital Medical School, London S.E.5.

\section{Introduction}

The best treatment for deep vein thrombosis of the legs has yet to be decided. Comparisons between homogeneous groups of patients receiving different treatments have seldom been reported and, with few exceptions (Robertson et al., 1968), rely on clinical signs for a measure of the effectiveness of treatment. This may be misleading, for clinical improvement is often complete despite persisting thrombus in the veins (Kakkar et al., 1968).

The purpose of this paper is to report the results of treatment in 30 patients who were allocated at random to one of three treatment schedules. One group was given the anticoagulant heparin. Another received the plasminogen activator streptokinase (Kabikinase), which is known to have a thrombolytic effect (Browse et al., 1968 ; Kakkar et al., 1968, 1969a). The third group was treated with Arvin, a purified fraction of the 
venom of the Malayan pit viper, which has a specific coagulant action on fibrinogen. The greatly reduced plasma fibrinogen concentration produced in patients receiving Arvin has been reported to have a beneficial anticoagulant action in thromboembolic disorders (Bell et al., 1963).

Two objective methods were used, as well as careful clinical observation, to study the fate of the thrombi. The presence of the thrombus was confirmed in each case by ascending functional phlebography (Kakkar and Flanc, 1968), and this was repeated frequently during treatment. The ${ }^{12.5}$ I-labelled fibrinogen test, known to be effective in the diagnosis of thrombosis (Atkins and Hawkins, 1965 ; Flanc et al., 1968 ; Negus et al., 1968), was extended by repeated observation to follow the decline in radioactivity concentrated over the thrombus. Repeated phlebograms have shown that the decline corresponds for the most part to dissolution of thrombi (Kakkar et al., 1968, 1969a).

\section{Materials and Methods}

\section{Selection of Patients}

Patients were considered for inclusion in the trial if they had signs and symptoms of deep vein thrombosis which had first appeared in the legs within the preceding four days.

Because the risk of bleeding would be accentuated at sites of already damaged vessels, no patient was treated within three days of operation or when extensive skin flaps were considered unhealed. Several with peptic ulcers were excluded, and also three with a diastolic blood pressure greater than $100 \mathrm{~mm}$. Hg.

Forty-two patients who satisfied all these criteria were referred from surgical and medical wards. All were examined by ascending functional phlebography; only when this confirmed the presence of thrombi in the deep veins of the leg was the patient admitted to the trial, and this was concluded as soon as the agreed number of 30 patients had been reached. The fallibility of clinical signs in this condition is highlighted by the fact that in 12 patients with a confident clinical diagnosis the $x$-ray films either failed to show thrombi or showed only trivial lesions in the tibial veins or soleal sinuses. These patients were excluded from further consideration.

\section{Design of the Trial}

Thirty envelopes were prepared, sealed, and numbered in sequence, each containing one of the three possible treatment schedules in random order. As each patient was admitted to the trial his treatment was selected by opening the next envelope. This gave three groups of 10 patients; the subsequent comparison between them shows that they were similar in many respects (Table I).

\begin{tabular}{|c|c|c|c|c|c|}
\hline & & & Heparin & Streptokinase & Arvin \\
\hline \multicolumn{3}{|c|}{ 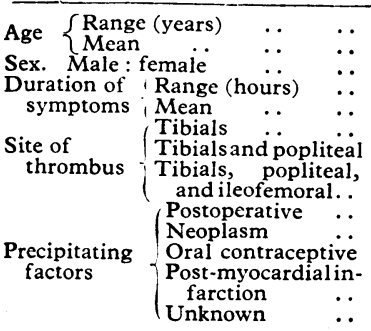 } & $\begin{array}{c}44 \text { to } 77 \\
58 \\
4: 6 \\
12 \text { to } 48 \\
38 \\
4 \\
1 \\
5 \\
5 \\
1 \\
0 \\
2 \\
2\end{array}$ & $\begin{array}{c}18 \text { to } 73 \\
50 \\
4: 6 \\
12 \text { to } 72 \\
52 \\
2 \\
1 \\
7 \\
8 \\
1 \\
0 \\
0 \\
1\end{array}$ & $\begin{array}{c}20 \text { to } 70 \\
58 \\
4: 6 \\
12 \text { to } 96 \\
54 \\
1 \\
2 \\
7 \\
7 \\
1 \\
2 \\
0 \\
1\end{array}$ \\
\hline
\end{tabular}

All the patients were confined to bed for the duration of the trial. The foot of the bed was raised, they were encouraged to move their legs as much as possible in bed, and they all wore thick elastic bandages, which were frequently reapplied to give external support. The selected drug was dissolved in $0.9 \%$ saline and given by continuous intravenous infusion, which was uninterrupted for five days unless the phlebograms showed complete clearance of thrombi before this, or unless complications arose. Infusions were often continued beycnd five days if thrombi were still visible on the phlebogram. At the end of infusion oral anticoagulants were given to all patients.

The treatment schedules were divided into loading and maintenance doses. Units are in each case those used by the manufacturer. (a) Heparin: loading, 10,000 units in five minutes ; maintenance, 10,000 to 15,000 units every six hours. (b) Streptokinase: loading, 500,000 units in 30 minutes; maintenance, 900,000 units every six hours. (c) Arvin: loading, 80 units in six hours followed by 80 units in 15 minutes; maintenance, 40 to 80 units every six hours.

These doses were chosen to produce certain definite effects, and blood samples were examined daily to ensure that these were in fact achieved. The methods used were those described by Alkjaersig et al. (1959) for plasminogen, by Ingram (1961) for fibrinogen, by Merskey et al. (1966) for fibrin degradation products, and by Kakkar et al. (1969a). The dose of heparin was increased within the agreed limits to prolong the thrombin clotting-time beyond the normal of 10 to 15 seconds, but reduced if the time exceeded 120 seconds. The high dose of streptokinase should be sufficient to reduce the plasma concentration of plasminogen to negligible amounts, so limiting the danger of excessive proteolysis. No patient required an adjustment of dose to produce this effect. Arvin was given to produce a plasma concentration of fibrinogen less than $50 \mathrm{mg}$./ $100 \mathrm{ml}$. In the last five patients in this group the maintenance dose was increased to the higher limit to make this certain.

\section{Assessment of Progress}

Clinical.-The patients were examined daily, and particular attention was paid to the extent of tenderness, the measured circumference of the limbs at various levels, their temperature, and the appearance of any new symptoms. The vital signs were recorded hourly for 24 hours, then every four hours.

Radiographic.-The details of ascending functional phlebography and its accuracy in demonstrating venous thrombi have been described elsewhere (Kakkar and Flanc, 1968). The procedure was repeated at about two-day intervals during treatment to show the extent of the thrombus.

Isotopic.-The technique followed that previously described in the diagnosis of thrombosis (Flanc et al., 1968). 12.I-labelled human fibrinogen when injected intravenously is incorporated into a forming thrombus. Repeated counts of radioactivity over the site of thrombus and over areas where there were no thrombi allowed a quantitative assessment of the fate of the thrombus (Kakkar et al., 1968, 1969a). The decrease in the percentage difference of radioactivity over these two sites indicated the rate of thrombus dissolution; this was confirmed by repeated phlebography.

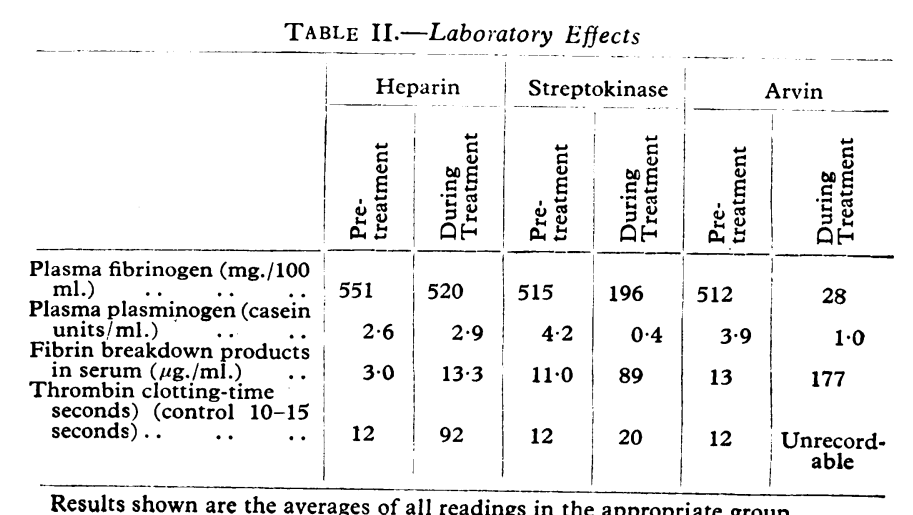

Results shown are the averages of all readings in the appropriate group. 


\section{Results}

Laboratory tests showed that the desired objectives were achieved by the agreed doses. They will be reported in detail elsewhere; the average results before and during treatment are shown in Table II.

Side-effects, clinical and radiographic results (Table III), and isotopic findings (Fig. I) are considered for each group in turn.

TABLE III.-Clinical and Radiographic Results

\begin{tabular}{|c|c|c|c|}
\hline & Heparin & Streptokinase & Arvin \\
\hline 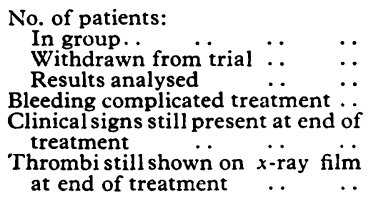 & $\begin{array}{l}10 \\
1^{*} \\
9 \\
2 \\
2 \\
7\end{array}$ & $\begin{array}{c}10 \\
1 \dagger \\
9 \\
3 \\
2 \\
3\end{array}$ & $\begin{array}{r}10 \\
0 \\
10 \\
1 \\
5 \\
9\end{array}$ \\
\hline $\begin{array}{l}\text { * Died of pulmonary embolism. } \\
\text { † Bleeding from venepuncture site } \\
\text { Frequency of complete thromboly } \\
\text { Streptokinase v. heparin + Arvi } \\
\text { Streptokinase v. Arvin } \\
\text { Streptokinase v. heparin } \\
\text { Heparin } \\
\text { v. Arvin }\end{array}$ & $\begin{array}{ll}x^{2} & 7 \cdot 3, \mathrm{P} \\
x^{2} & 6 \cdot 5, \mathrm{P} \\
x^{2} & 3 \cdot 6,0 \\
x^{2} & 0 \cdot 5,0\end{array}$ & $\begin{array}{l}1 \\
25 \\
>0.05 \\
>0.4\end{array}$ & \\
\hline
\end{tabular}

\section{Heparin Group}

One patient died from a massive pulmonary embolus which occurred 36 hours after the beginning of treatment. The remaining nine patients all completed at least five days of treatment and for many the infusion was continued longer, as the original thrombus was then unchanged.

Treatment of two patients had to be stopped because of bleeding; a large retroperitoneal haemorrhage occurred on the seventh day and caused renal failure from which the patient later died ; another patient developed melaena, which required the injection of protamine and the transfusion of 5 pints $(2 \cdot 8$ litres) of blood for its control. There were no other complications.

The majority of patients showed rapid clinical improvement, and all but two of the nine were free from signs and symptoms after six days. The radiographic findings emphasize the inadequacy of this clinical assessment. The original thrombi had cleared completely in two patients, but were unchanged in five and only slightly less extensive in the other two. The decline of radioactivity over the sites of thrombi in six of the patients (Fig. 1a) shows a rapid fall for two with complete clearance judged by phlebography, an intermediate fall for one with partial clearance, and a slower reduction, sometimes preceded by a rise, for three whose thrombi appeared unchanged.

\section{Streptokinase Group}

One patient had to be excluded, as bleeding from the site of subclavian venepuncture prevented an adequate course of treatment. This leaves nine patients for analysis.

Bleeding was also a feature $c^{c}$ three of these cases, and was severe enough to call for neutralization of the circulating activator with aminomethyl-cyclohexane carboxylic acid (Cyklokapron) in two-a patient with accentuation of otherwise normal menstrual bleeding and a patient who bled from the site of radical vulvectomy. The extensive unhealed wound in the latter patient was seven days old before the start of infusion with streptokinase, but bleeding began on the sixth day of treatment. Four patients developed a rise in temperature of between 2 and $5^{\circ} \mathrm{F}$. $\left(1 \cdot 1\right.$ and $2 \cdot 8^{\circ} \mathrm{C}$.), often with rigors, during the first 48 hours. Acute dyspnoea and tachycardia occurred in two patients during the administration of the loading-doses, but these were rapidly controlled by the intravenous administration of $10 \mathrm{mg}$. of chlorpheniramine maleate (Piriton).

As with the heparin group, clinical signs rapidly disappeared in the majority and only two of the nine had any residual symptoms at the end of the infusion. In contrast to the heparin group the radiographic findings correlated well with the clinical signs. Six patients showed complete clearance of all thrombi (Special Plate, Fig. 1), in one case as early as one day and usually by the fifth day of treatment. Another patient showed substantial but still incomplete thrombolysis after eight days, but the two with residual signs still retained their original extensive thrombi. Both were complicated cases in which local stimuli to rethrombosis were present-one had peritonitis consequent on mesenteric artery thrombosis and the other was the radical vulvectomy patient. Both subsequently died. The isotopic studies in Fig $1 \mathrm{~b}$ show a rapid fall of radioactivity in six of the patients who improved and the persistence of radioactivity in the two failures.
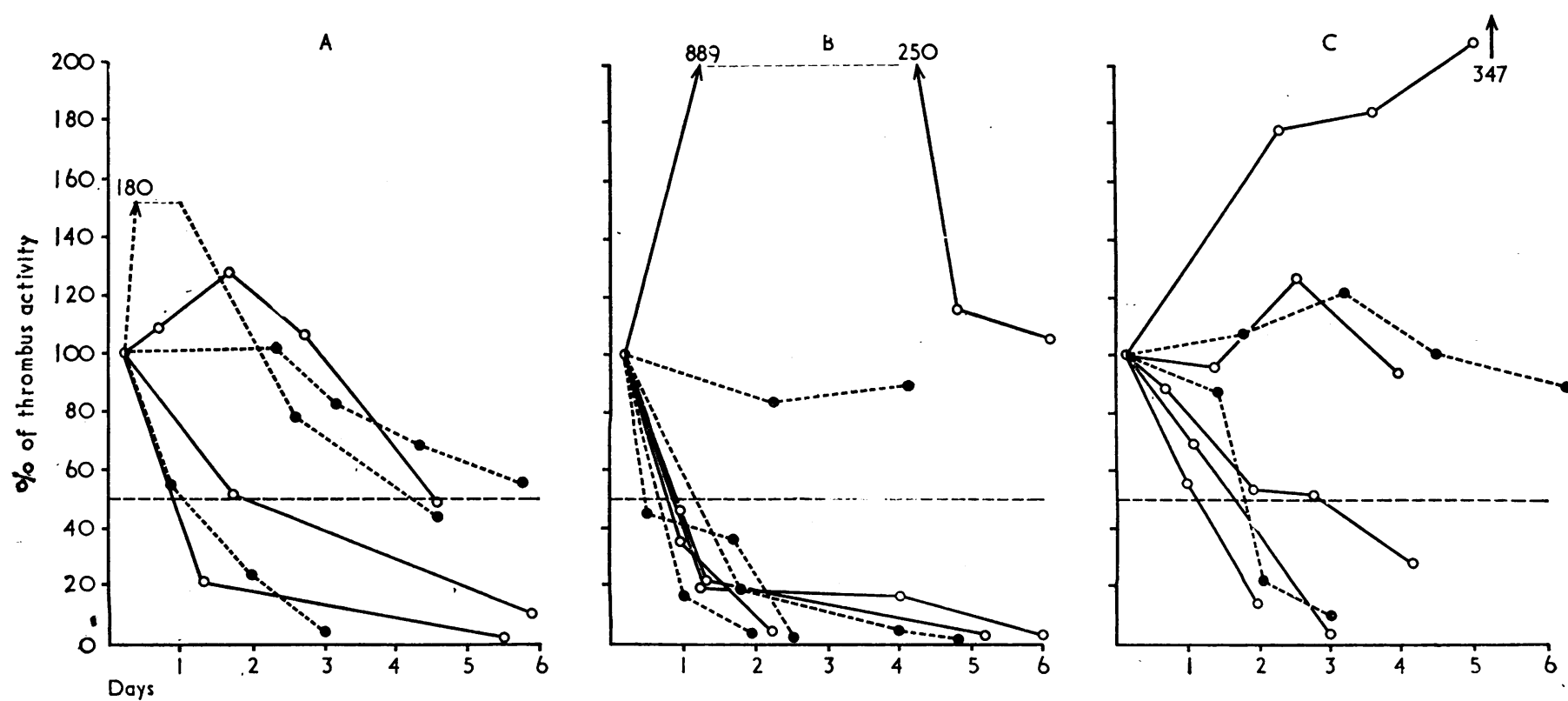

FIG. I-Changes in radioactivity. (a) Six patients treated with heparin. (b) Eight patients treated with streptokinase. (c) Seven patients treated Fit. - . area where no thrombus is present. 
V. V. KAKKAR $E T A L .:$ TREATMENT OF DEEP VEIN THROMBOSIS

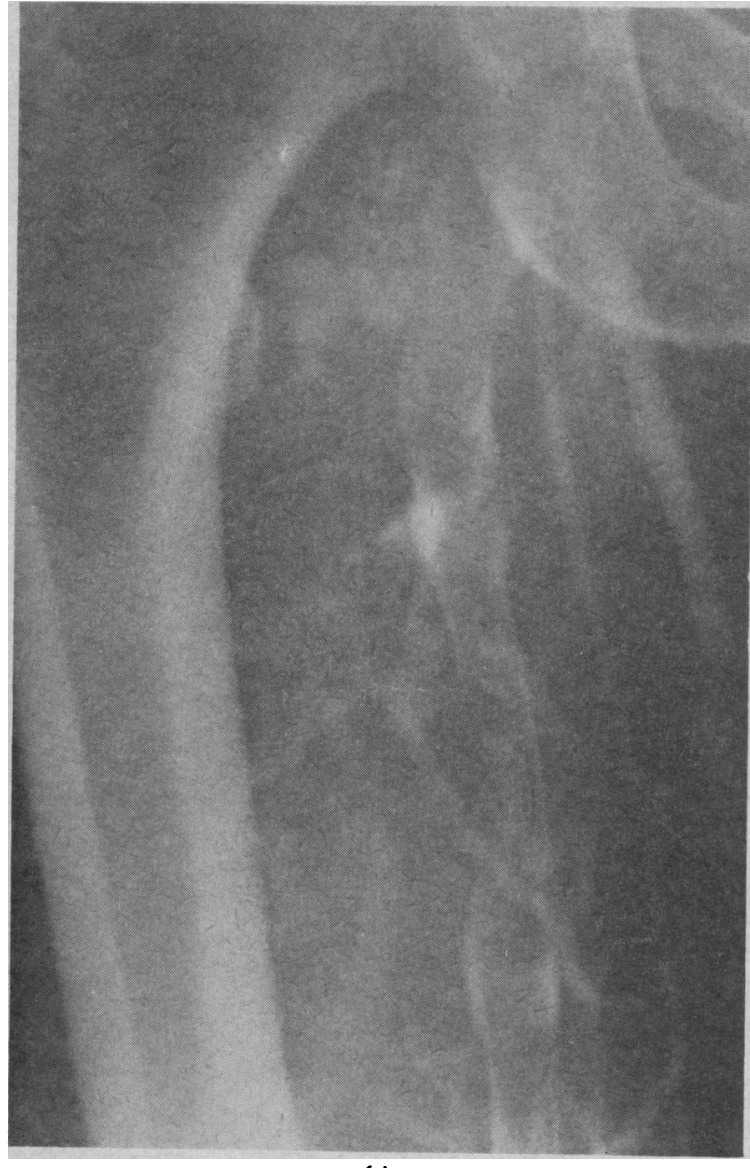

(a)
FIG. 1.-Phlebogram (a) before treatment, shows consistent failure of the femoral vein to fill with contrast medium and represents almost complete occlusion of the femoral vein; (b) after streptokinase therapy, there is uniform filling of the femoral vein representing complete representing complete clearance. Both cusp
of the valves are seen.

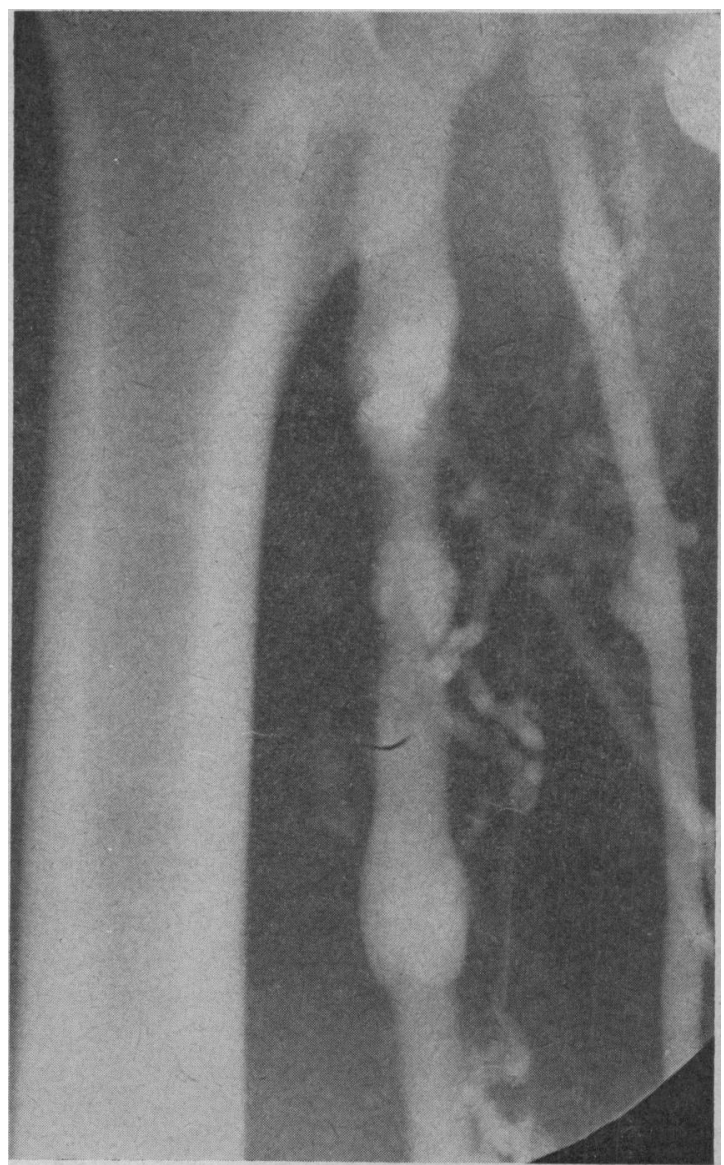

(b)

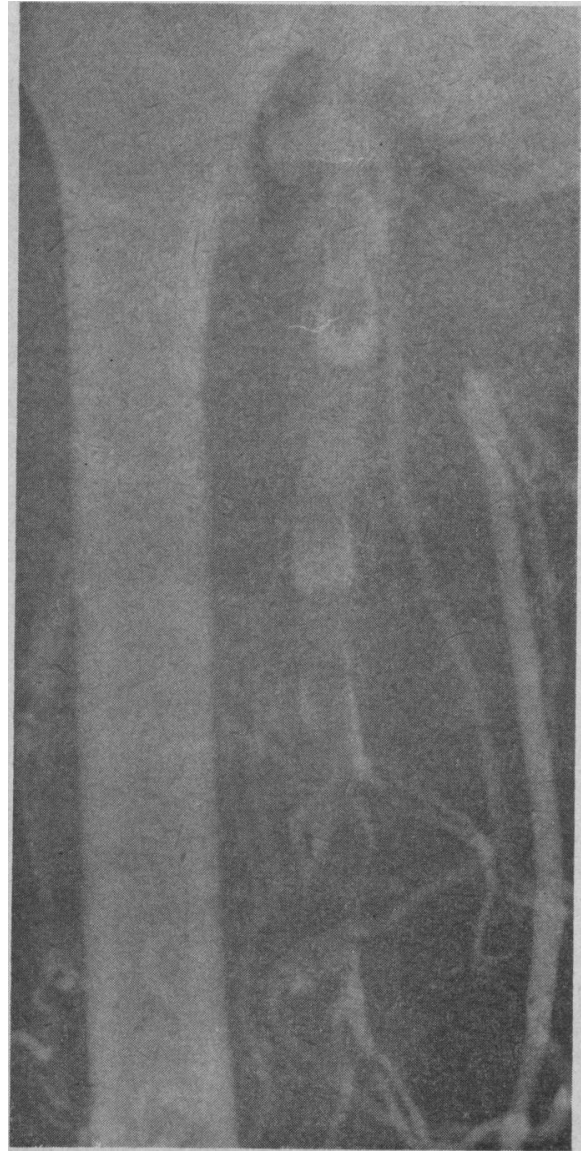

FIG. 2.-Phlebogram (a) before treatment, shows extensive thrombosis in the femoral vein ; $(b)$ after seven days of Arvin therapy, shows complete occlusion of the femoral vein and proximal portion of the long saphenous vein. 


\section{Arvin Group}

All patients completed five days of treatment and many continued longer. There were only two complications. On the twelfth day of treatment one patient suffered from a small melaena which did not require transfusion. Another, a patient with severe asthma, developed an acute confusional state of uncertain causation on the fifth day of treatment. This rapidly resolved when the infusion was stopped. Ten patients were therefore available for analysis.

Symptoms resolved before the end of treatment in all but three of the patients, but, as in the heparin group, there was no correlation with the radiographic findings. Complete thrombolysis was shown only once. In six patients the thrombi were at least as extensive as before the treatment ; in three there was partial dissolution. Isotopic findings (Fig. 1c) largely correlated with the radiographic results. Persistent or increasing radioactivity at the site of thrombus was recorded in three of the patients with no phlebographic improvement (Special Plate, Fig. 2). Four patients showed a progressive reduction in radioactivity, and phlebograms showed complete clearance in one and partial clearance in the remainder.

\section{Discussion}

The need to set the management of deep vein thrombosis on a sound basis has been given added urgency by the recent development of the radioisotopic method of diagnosis. This technique when used routinely to screen patients in medical and surgical wards can reveal the onset of deep vein thrombosis at a very early stage, when the process is limited in extent and very often asymptomatic (Kakkar et al., 1968 ; Negus et al., 1968). Not until the natural history of these very early thrombotic lesions is known in more detail will it be possible to assert with confidence what the treatment should be.

Only patients with extensive deep vein thrombosis were included in this trial. Pulmonary embolism had already occurred before treatment in 10 of the patients. In a few the viability of the limb was in question. The aim of the study was to measure as objectively as possible the rate and completeness of removal of thrombi following different forms of therapy.

The results show that thrombolysis is more effective with streptokinase than with either heparin or Arvin, and the findings in the following paper confirm this conclusion (Kakkar et al., 1969b). There seems little to choose between heparin and Arvin as regards their anticoagulant potential.

In this series, even when patients at risk from haemorrhage were excluded, heparin was associated with bleeding on two occasions. The obvious nature of bleeding to the exterior and its easy control with protamine does not make this a serious danger, but internal bleeding may damage vital organs, or, if recognition is only slightly delayed, lead to death, as in one case in this trial. The group showing the least side-effects was undoubtedly that treated with Arvin; slight bleeding was noticed only once. Streptokinase, but not heparin or Arvin, increased menstrual bleeding to alarming proportions, and the presence of menstruation should probably be added to the list of contraindications for this drug; similarly, the existence of extensive raw areas, however long-standing, as exemplified by the bleeding which followed radical vulvectomy. Nevertheless, closely apposed wound edges gave no trouble if the infusion was delayed for three days after operation. It should be emphasized that the risk of bleeding due to streptokinase is known to be associated with the products of the proteolysis of fibrinogen in the plasma (Verstraete et al., 1966), and these are usually at their peak during the first 24 hours. External bleeding is rapidly controlled by stopping the infusion and injecting one of the synthetic inhibitors of fibrinolysis ; aminomethyl-cyclohexane carboxylic acid was very effective in this series. Again this is not necessarily true of internal bleeding, as the damage may be done before it is recognized. Pyrexia and immediate allergic reactions were also very troublesome with streptokinase. Prophylactic hydrocortisone was not used on this occasion, since we had found it to be of little use in a previous study (Kakkar et al., 1969a).

There is no certainty that the high initial dose of streptokinase used here, as recommended by Verstraete et al. (1966) for the treatment of arterial thrombosis, is necessarily the best regimen. Close laboratory supervision is still necessary to give forewarning of a likely bleeding episode. This would perhaps be most obvious when the presence of excessive products of fibrinogenolysis cause an unusual prolongation of the thrombin clotting-time. Another disadvantage of streptokinase is its ability to form neutralizing antibodies in high titre which for a time at least would preclude a second course in the same patient (Flute, 1964).

Even streptokinase is not uniformly successful. Factors known to affect its action are the extent and the age of the thrombus. Since the activator must reach the thrombus to produce the desired effect, thrombolysis is achieved more readily in a vessel which is not completely occluded. However, many veins were completely obstructed by thrombus in this series and still showed complete clearance, and it seems that the age of the thrombus is likely to have the greater effect. Much may also depend on the intensity of any continuing stimulus to fibrin formation such as local inflammation. Peritonitis and a wound over the femoral veins probably account for the two failures in the streptokinase group.

Repeated phlebography to follow progress is useful in indicating when to stop an infusion of streptokinase. The earliest response was after one day and the latest after eight days of treatment. A useful supplement to phlebography is the isotopic test with radioactive fibrinogen. No side-effects were encountered with the technique. The decline of local radioactivity closely followed the dissolution of thrombi as shown on repeated phlebograms, except in one of the 21 patients studied by this method. These results are very similar to previous findings by Kakkar et al. (1968, 1969a).

It remains to summarize our present practice in the management of a patient with extensive deep vein thrombosis. Phlebography and radioactive counts are performed to establish the diagnosis and repeated to follow the fate of the thrombus. If there is no contraindication streptokinase is given to these patients. If streptokinase is not used there is little to choose between heparin or Arvin, but it seems that Arvin may be easier to control and has fewer side-effects. Thrombectomy is considered only in those patients in whom streptokinase or anticoagulants are contraindicated or have failed.

We are grateful to Professor J. G. Murray and the physicians and surgeons of King's College Hospital for their help and encouragement; to the Hospital Research Trust and to Pfizer Ltd. for financial support ; to Kabi Pharmaceuticals Ltd. for supplies of Kabikinase, Cyklokapron, and human fibrinogen ; and to Twyford Laboratories for supplies of Arvin. Miss Gillian Pannell and Mr. S. Serunkuma gave invaluable technical assistance. We thank Mr. C. Redman for the photography.

\section{REFERENCES}

Alkjaersig, N., Fletcher, A. P., and Sherry, S. (1959). 7. clin. Invest., 38, 1086.

Atkins, P., and Hawkins, L. A. (1965). Lancet, 2, 1217.

Bell, W. R., Pitney, W. R., and Goodwin, J. F. (1968). Lancet, 1, 490. Browse, N. L., Thomas, M. L., and Pim, H. P. (1968). Brit. med. F., 3, 717.

Flanc, C., Kakkar, V. V., and Clarke, M. B. (1968). Brit. F. Surg., 55,

Flute, P. T. (1964). F. clin. Path., 17, 333.

Ingram, G. I. C. (1961). F. clin. Path., 14, 356. 
Kakkar, V. V., and Flanc, C. (1968). Brit. F. Surg., 55, 384.

Kakkar, V. V., Flanc, C., O'Shea, M., Flute, P., Howe, C. T., and Clarke, M. B. (1968). Brit. Ұ. Surg., 55, 858.

Kakkar, V. V., Flanc, C., O'Shea, M., Flute, P. T., Howe, C. T., and Clarke, M. B. (1969a). Brit. 尹. Surg., 56, 178.

Kakkar, V. V., Howe, C. T., Laws, J. W., and Flanc, C. (1969b). Brit. med. F., $1,810$.
Merskey, C., Kleiner, G. J., and Johnson, A. J. (1966). Blood, 28, 1. Negus, D., Pinto, D. J., Le Quesne, L. P., Brown, N., and Chapman, M. (1968). Brit. F. Surg., 55, 835.

Robertson, B. R., Nilsson, I. M., and Nylander, G. (1968). Acta chir. scand., 134, 203.

Verstraete, M., Vermylen, J., Amery, A., and Vermylen, C. (1966). .Brit. med. F., $1,454$.

\title{
Late Results of Treatment of Deep Vein Thrombosis
}

\author{
V. V. KAKKAR,* F.R.C.S., F.R.C.S.ED.; C. T. HOWE,† F.R.C.S. ; J. W. LAWS, F F.R.C.P., F.F.R. \\ C. FLANC, $\S$ F.R.A.C.S.
}

[With Special Plate facing Page 809]

Brit. med. F., 1969, 1, 810-811

Summary: Twenty-two patients who had an acute episode of thrombosis in the deep veins of the legs were studied by a new technique of ascending functional cinephlebography 6 to 12 months after the episode of thrombosis.

If the condition was diagnosed within 36 hours and the thrombus was dissolved rapidly valve function was preserved. When diagnosis was delayed there was a very great risk of permanent damage to the valves.

\section{Introduction}

The preceding article (Kakkar et al., 1969) described the immediate results of the treatment of deep vein thrombosis of the legs, in which the dominant complication was the risk to life from pulmonary embolism. By contrast, this paper is concerned with the long-term sequelae. When thrombosed veins recanalize, the valves are either destroyed (Edwards and Edwards, 1937) or they become incompetent, resulting in a sustained high pressure in the veins of the legs (Beecher, 1937 ; Linton and Hardy, 1948). Subsequently there may follow pain in the legs, swelling, varicose veins, eczema, ulceration, and other trophic changes.

In the present study 22 patients with deep vein thrombosis who had been treated during the acute phase with heparin, streptokinase, or Arvin were followed up in an attempt to answer the following questions: What form of initial treatment was most successful in the eventual return of the veins to normal? What are the critical factors involved in the preservation of function of venous valves?

\section{Materials and Methods}

Twenty-two patients (described in the preceding paper) have so far been restudied after an interval of up to 12 months after the initial treatment with heparin, streptokinase, or Arvin (see Table). In eight patients who had complete clearance (see Table) long-term oral anticoagulant therapy was not used. Of 14 patients in whom there was partial clearance after the initial treatment eight had oral anticoagulants for six to nine months

- Pfizer Research Fellow, now Senior Surgical Registrar.

t Senior Lecturer and Consultant Surgeon.

¥ Director, Department of Radiology.

F Director, Department of Rent of Surgery.

King's College Hospital Medical School, London S.E.5. and six had none. The dose of oral anticoagulant was regulated to maintain the prothrombin time between one and a half and twice the control value, rabbit brain thromboplastin being used.

The legs were re-examined several months after the original treatment by ascending functional cinephlebography-a technique which was developed to show valvular function and completeness of recanalization.

\section{Ascending Functional Cinephl:bography}

The patient lies on a fluoroscopic $x$-ray table which is tilted to an angle of 60 degrees to the horizontal. A pneumatic cuff is placed just above the ankle, and is distended to a pressure of $100 \mathrm{~mm} . \mathrm{Hg}$ in order to prevent filling of the superficial veins of the leg and to direct the contrast medium into the deep venous system. A scalp-vein $21 \mathrm{G}$ thin-wall (20G bore) infusion cannula is introduced into a vein on the dorsum of the great toe; this vein is selected because it is easy to cannulate and directly joins the plantar plexus through the first interosseous space. Therefore any contrast medium which is injected through this vein flows directly into the deep veins. The cannula is attached to a $50-\mathrm{ml}$. syringe filled with $45 \%$ sodium diatriozate which has been warmed to body temperature, and the contrast medium is injected slowly. The patient is instructed to plantar flex and dorsiflex the foot in order to propel the contrast medium. As the contrast medium progresses in the tibial veins, continuous observations are made on the television monitor. The function of the valves, seen on the television monitor, is recorded on both cine and static films. The contrast medium is now followed into the popliteal and femoral veins and the function of their valves is assessed. The effect of the Valsalva manœuvre on these valves is also recorded. Lastly, the contrast medium is followed into the iliac veins to confirm their patency. At the end of the examination the contrast medium is washed out of the deep veins by $150 \mathrm{ml}$. of normal saline containing 2,500 units of heparin. Clearance is confirmed by screening the leg.

The valvular function was considered to be normal when both the valve cusps were seen to open and close with onward flow of blood and no retrograde flow occurred. It was considered that function was poor when the valve cusps were present but did not open and close and retrograde flow occurred. A completely recanalized vein was evenly filled with contrast medium and had a smooth lumen. Recanalization was considered to be incomplete when filling of the vein was constantly uneven with an irregular lumen. 